\title{
Evaluation of retrobulbar blood flow in patients with age-related cataract; color Doppler ultrasonographic findings
}

This article was published in the following Dove Press journal:

Clinical Ophthalmology

I4 October 201 I

Number of times this article has been viewed

\section{Afshin Mohammadi ${ }^{1}$ \\ Nilofar Khorasani ${ }^{2}$ \\ Farzad Moloudi ${ }^{2}$ \\ Mohammad Ghasemi-rad ${ }^{3}$ \\ 'Department of Radiology, Urmia University of Medical Sciences, Urmia, Iran; ${ }^{2}$ Student Research Committee, Urmia University of Medical Sciences, Urmia, Iran; ${ }^{3}$ Genius and Talented Student Organization, Student Research Committee, Urmia University of Medical Sciences, Urmia, Iran}

Objectives: Cataracts are the most common cause of blindness worldwide, with cataract surgery being the most common ophthalmic procedure. To our best knowledge, this is the first case-control study with a large number of participants to evaluate ocular blood flow in patients with cataracts.

Materials and methods: Color Doppler and duplex sonography of the orbital vessels was performed in 224 eyes of 112 patients with known bilateral age-related cataracts and in 76 eyes of 38 healthy age- and sex-matched volunteers.

Results: The mean \pm (standard deviation [SD]) of peak systolic velocity (PSV) of the ophthalmic artery in patients with cataracts $(34.59 \pm 22.49 \mathrm{~cm} / \mathrm{second})$ was significantly different to that in controls $(52.11 \pm 14.01 \mathrm{~cm} / \mathrm{second})(P<0.001)$. The mean \pm SD PSV of the central retinal artery in patients with cataracts $(15.31 \pm 4.93 \mathrm{~cm} /$ second $)$ was significantly different to that in controls $(9.61 \pm 5.64 \mathrm{~cm} / \mathrm{second})(P<0.001)$.

Conclusion: The mean PSV and resistive index (RI) of the ophthalmic and central retinal arteries were lower in cataract patients when compared with normal subjects. This suggests that ocular hypoperfusion and changes in ocular hemodynamic may have a role in the formation of age-related cataracts.

Keywords: retrobulbar blood flow, age-related, cataract, color Doppler ultrasonographic

\section{Introduction}

Cataracts are considered the most common cause of blindness worldwide, with cataract surgery being the most common ophthalmic procedure. ${ }^{1,2}$ According to World Health Organization (WHO) reports nearly 40 million people will be affected by age-related cataracts by $2020 .{ }^{3}$ Cataracts have been reported to be associated with mortality; this is thought to be due to diabetes mellitus and hypertension causing both cataract and mortality. ${ }^{4,5}$ The most common causes for cataract development are acquired. Senile or age-related cataract is the cause for most acquired cataracts. Genetic and environmental factors also contribute to the development of cataracts, ${ }^{6}$ and although the type of cataract and associated risk factors have not been fully established, age, ${ }^{7}$ smoking, ${ }^{8}$ diabetes mellitus, ${ }^{9}$ sunlight exposure, ${ }^{10}$ alcohol use, ${ }^{11}$ metabolic syndrome, ${ }^{12}$ and corticosteroid use, ${ }^{13}$ have generally been identified. The roles of hypertension and cardiovascular risk factors still remain unclear. ${ }^{14}$

Color Doppler imaging of orbital vessels is a procedure that has been recently used for detecting various ocular disorders such as glaucoma, central retinal vein occlusion, and tumors of the eye and orbit, and is gaining popularity because of improvements in detecting and measuring blood flow velocities in the orbital vessels. ${ }^{15}$ Measurements of the flow velocity of the ophthalmic artery (OA), central retinal artery (CRA),
Correspondence: Mohammad Ghasemi-rad Genius and Talented Student Organization, Student Research Committee, Urmia University of Medical Sciences, Urmia, Iran

$\mathrm{Tel}+989143485284$

Fax +98 44|235356|

Email medmanII@gmail.com 
central retinal vein (CRV), and posterior ciliary arteries are possible using color Doppler ultrasonography. ${ }^{16}$ It is believed that there are changes in ocular blood flow in patients with cataracts. Only one case-control study which involved a small number of patients unmatched with respect to age has been performed previously to establish this relationship, ${ }^{17}$ and other reports studied the effects of local anesthesia on ocular blood flow. ${ }^{18-20}$ To our best knowledge, this is the first case-control study with a large number of participants to evaluate ocular blood flow in patients with cataracts. In this study, we tried our best to exclude all confounding factors that may have interfered with the association between ocular blood flow and cataract development.

\section{Materials and methods}

Color Doppler and duplex sonography of the orbital vessels was performed in 224 eyes of 112 patients with known bilateral age-related cataract and in 76 eyes of 38 healthy ageand sex-matched volunteers. Informed consent was obtained from all subjects before examination and the University Review Board and Ethic Committee approved the study.

Cataracts were diagnosed on the basis of complete ophthalmologic examination by an experienced ophthalmologist. Patients with high myopia, retinal and vitreous pathology traumatic cataract, steroid treatment, hypertension, diabetes mellitus, history of smoking, any systemic disease, previous cataract surgery or any ocular surgery, and corticosteroid therapy were excluded from the study.

One radiologist experienced in Doppler sonography performed all ultrasound examinations. The sonographer was blinded to the presence of cataract or any relevant clinical data about the patients and the controls.

The patients were examined in a supine position with both eyes closed. The transducer was applied gently by using a sterile coupling gel to the closed eyelids; care was taken to avoid applying any pressure to the eye. We ask the patients to look forward during the ultrasound examination to prevent eye movements.

Ultrasound examination was performed on the sagittaloblique plane to determine the optimal long axis of the orbital vessels posterior to the eye. To accurately measure flow velocity, the Doppler angle was kept between $30^{\circ}$ and $60^{\circ}$. The proximal and distal portions of the vessels were imaged to facilitate the determination of the Doppler flow angle and the estimation of true flow velocity.

The ophthalmic artery enters the orbit via the optic foramen, lateral and slightly inferior to the optic nerve. After crossing the superior margin of the nerve, it typically proceeds anteriorly on the medial side of the orbit.
Because the anatomy of the orbital vasculature is highly complex and it is not possible to evaluate the ophthalmic artery at the canalicular portion, we measured the Doppler indices after the ophthalmic artery was crossed by the optic nerve (intraorbital continuation of ophthalmic artery) close to the medial wall of the orbit, since it is the best place to set the Doppler angle below $60^{\circ}$.

Doppler indices in the intraorbital continuation of the ophthalmic and central retinal arteries were measured with a Siemens Sonoline G-40 ultrasound device using a $10 \mathrm{MHz}$ linear phase array transducer (Munich, Germany). Flow settings were chosen according to the velocity of the vessels, ie, for the ophthalmic artery, medium-to-high settings and for the central retinal artery, low-settings. Color gain and sensitivity were adjusted to minimize the artifact due to eyelid or eyeball movements.

The peak systolic velocity (PSV), end diastolic flow velocity (EDV) and resistive index (RI) $(\mathrm{RI}=\mathrm{PSV}-\mathrm{EDV} / \mathrm{PSV})$ were measured in the central retinal artery (Figure 1) and the intraorbital continuation of ophthalmic artery (Figure 2). Examinations took about 10 minutes on average. Each measurement was repeated three times and the mean of each measurement was calculated.

Statistical significance was set at $P<0.05$. SPSS for Windows (v 16.0; SPSS Inc, Chicago, IL) was used for all data analyses. Continuous variables were reported as mean \pm (standard deviation [SD]) and categorical variables were reported as frequencies. Independent $t$-tests were used for analysis and a $P$ value of less than 0.05 was considered statistically significant.

\section{Results}

Our study included 112 patients with 224 eyes (53 female, 59 male) and 38 controls with 76 eyes (17 female, 21 male).

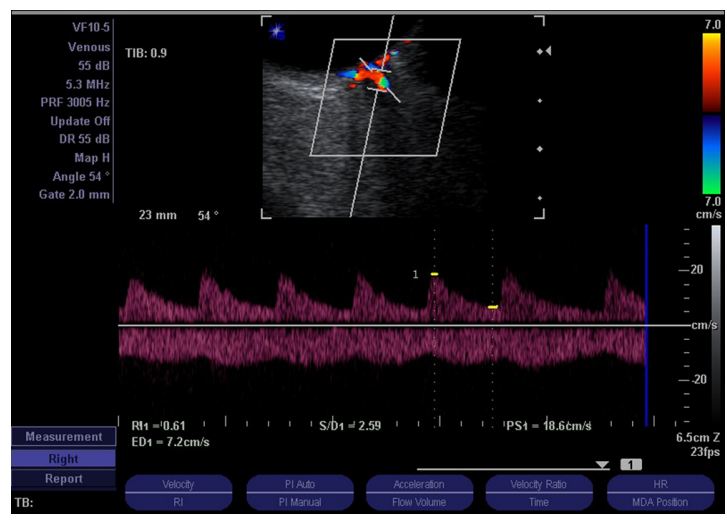

Figure I Color Doppler ultrasonogram showing central retinal artery spectral Doppler waveform in a cataract patient. The resistive index was 0.61 . 


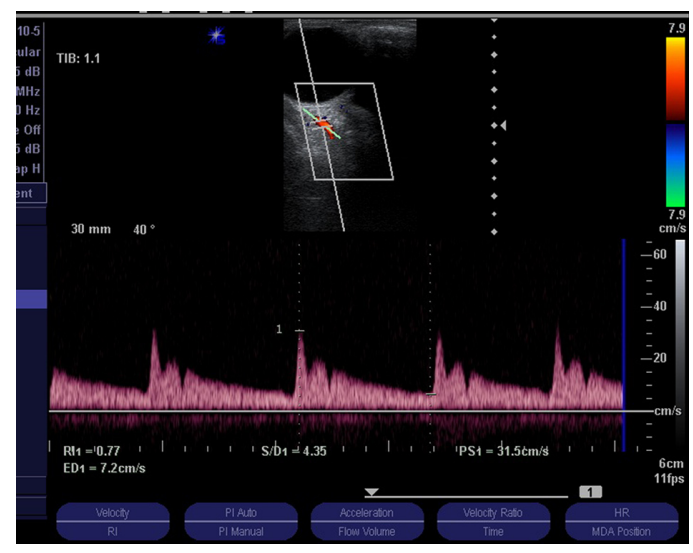

Figure 2 Color Doppler ultrasonogram showing central retinal artery spectral Doppler waveform of the ophthalmic artery in a normal subject. The resistive index was 0.77 .

The mean \pm SD age of patients with cataracts was $67.11 \pm 9.6$ years and for the control group was $69.86 \pm 10.84$ years. There was no significant difference between the groups in terms of sex and age distribution $(P=0.6)$.

The mean \pm SD PSV of the ophthalmic artery in patients with cataracts $(34.59 \pm 22.49 \mathrm{~cm} / \mathrm{second})$ was significantly different to that in the controls $(52.11 \pm 14.01 \mathrm{~cm} / \mathrm{second})$ $(P<0.001)$.

The mean \pm SD PSV of the central retinal artery in patients with cataracts $(15.31 \pm 4.93 \mathrm{~cm} / \mathrm{second})$ was significantly different to that in the controls $(9.61 \pm 5.64 \mathrm{~cm} /$ second) $(P<0.001)$.

The mean \pm SD RIs in OA and CRA in patients with cataract were $0.67 \pm 0.07$ and $0.61 \pm 0.09$, respectively and in controls were $0.81 \pm 0.04$ and $0.78 \pm 0.05$, respectively. Both differences were statistically significant $(P<0.001)$. All duplex indices are summarized in Table 1.

\section{Discussion}

Cataract is defined as any opacity in the lens and is the leading cause of visual impairment worldwide. Because of recent

Table I Duplex indices in the central retinal and ophthalmic arteries in cases and controls

\begin{tabular}{lccl}
\hline Doppler indices & $\begin{array}{l}\text { Cataract } \\
\text { groups }\end{array}$ & $\begin{array}{l}\text { Control } \\
\text { groups }\end{array}$ & P value \\
\hline PSVOA (cm/second) & $34.59 \pm 22.49$ & $52.1 \mathrm{I} \pm \mathrm{I} 4.0 \mathrm{I}$ & $0.00 \mathrm{I}$ \\
PSVCRA (cm/second) & $9.6 \mathrm{I} \pm 5.64$ & $15.3 \mathrm{I} \pm 4.93$ & $0.00 \mathrm{I}$ \\
EDVOA (cm/second) & $10.60 \pm 4.36$ & $10.44 \pm 5.96$ & 0.7 \\
EDVCRA (cm/second) & $3.50 \pm 1.13$ & $3.35 \pm \mathrm{I} .28$ & 0.3 \\
RI OA & $0.67 \pm 0.07$ & $0.8 \mathrm{I} \pm 0.04$ & $0.00 \mathrm{I}$ \\
RI CRA & $0.6 \mathrm{I} \pm 0.09$ & $0.78 \pm 0.05$ & $0.00 \mathrm{I}$ \\
\hline
\end{tabular}

Abbreviations: PSVOA, peak systolic velocity of ophthalmic artery; PSVCRA, peak systolic velocity of central retinal artery; EDVOA, end diastolic velocity of ophthalmic artery; EDVCRA, end diastolic velocity of central retinal artery; RI OA, resistive index of ophthalmic artery; RI CRA, resistive index of central retinal artery. advances in treatment of infectious causes of blindness, the percentage of age-related causes of blindness is increasing. ${ }^{21}$ The prevalence of cataracts is $50 \%$ in the $65-74$ years age group and $70 \%$ after 75 years of age. ${ }^{1}$ Apart from aging, there are factors in developing cataract such as; trauma, toxins, diabetes mellitus, corticosteroid use, smoking, and hereditary cataracts. ${ }^{1}$

The pathophysiology of cataract development is not clearly defined. Some factors include oxidative damage from free radicals, ultraviolet radiation from sunlight, and malnutrition. ${ }^{22}$ Age-related cataracts are classified as nuclear sclerosis, cortical cataracts, and posterior subcapsular cataracts. ${ }^{1}$ Glare and visual impairment are common symptoms of age-related cataracts.

For the past 40 years, ultrasound has been used as a diagnostic tool for diseases of the eyeball and orbit. The earliest application of ultrasound in orbital pathology was amplitude (A) mode devices in which echoes appeared as spikes, the magnitude of which were dependent on the density of the reflecting tissue. Next, ultrasound was developed to detect intraocular tumors, vitreous hemorrhages, retinal detachment, and foreign bodies. ${ }^{4}$ Color and duplex Doppler imaging are used for the evaluation of normal vascular anatomy, vascular flow in ocular tumors, traumatic injury, and detection of vascular malformations and arteriovenous fistulae. Modern ultrasound devices have been improved regarding image resolution and are an important part of ophthalmologic evaluations.

Peak systolic velocity, end diastolic velocities, and RI that are independent of the Doppler angle are commonly measured. RI provides quantitative measurement of flow patterns for evaluation and for comparing the resistance of the vascular bed.

Because aging has a major role in the development of agerelated cataracts ${ }^{4,8}$ we enrolled age-matched control subjects in order to have a homogenous study population.

According to previous studies, smoking has a direct relationship with the development of nuclear cataracts, and this correlation is dose dependent. ${ }^{4,7,9}$ A previous study has revealed that the effect of smoking on the formation of cataracts is limited to those with nuclear cataracts rather than non-nuclear cataracts. ${ }^{8}$ Because of controversies about the role of smoking in cataract formation, we selected patients and controls without a history of smoking to omit the possible role of this confounding factor.

Based on our study results, the mean RI of the ophthalmic and central retinal arteries in patients with cataracts is lower compared to the control group. In this report, we measured 
RI as an indication of the quality of blood flow to the orbit and not ocular blood volume, which is a quantitative assessment.

An earlier study showed that changes in ocular blood flow could be a risk factor in the development of glaucoma. ${ }^{23} \mathrm{We}$ know that one of the main theories about the etiology of agerelated cataracts is oxidative damage, and some recent studies have suggested using carotenoids for protection. ${ }^{1}$ According to this theory, hypoperfusion and reduction in oxygen and delivery of nutrients to the eyes may have an important role in the formation and elimination of free radicals.

The results of PSV in the ophthalmic artery in our study are in agreement with the results of another study. Grieshaber et $\mathrm{al}^{17}$ performed a study on a small series of patients with cataracts (confounding factors were not excluded and patients and controls were not age-matched) and showed that the mean PSV was significantly lower in cataract patients than in controls. The mean RI of the ophthalmic artery in both groups was not statistically different. ${ }^{17}$ In contrast, our study showed that the mean RI in the two groups was statistically different $(P<0.001)$. One of the limitations of our study is the absence of grading of the cataracts and its correlation with the Doppler study.

In conclusion, the mean PSV and RI of the ophthalmic and central retinal arteries in patients with cataracts were lower than in normal subjects. This suggests that ocular hypoperfusion and changes in ocular hemodynamics may play roles in the formation of age-related cataracts.

\section{Disclosure}

The authors report no conflicts of interest in this work.

\section{References}

1. West SK. Looking forward to 20/20: a focus on the epidemiology of eye diseases. Epidemiol Rev. 2000;22(1):64-70.

2. Keeffe JE, Taylor HR. Cataract surgery in Australia 1985-1994. Aust N Z J Ophthalmol. 1996;24(4):313-317.

3. Brian G, Taylor H. Cataract blindness - challenges for the 21 st century. Bull World Health Organ. 2001;79(3):249-256.

4. West SK, Munoz B, Istre J, et al. Mixed lens opacities and subsequent mortality. Arch Ophthalmol. 2000;118(3):393-397.

Clinical Ophthalmology

\section{Publish your work in this journal}

Clinical Ophthalmology is an international, peer-reviewed journal covering all subspecialties within ophthalmology. Key topics include: Optometry; Visual science; Pharmacology and drug therapy in eye diseases; Basic Sciences; Primary and Secondary eye care; Patient Safety and Quality of Care Improvements. This journal is indexed on Submit your manuscript here: http://www.dovepress.com/clinical-ophthalmology-journal
5. Wang JJ, Mitchell P, Simpson JM, Cumming RG, Smith W. Visual impairment, age-related cataract, and mortality. Arch Ophthalmol. 2001;119(8):1186-1190.

6. Hammond CJ, Snieder H, Spector TD, Gilbert CE. Genetic and environmental factors in age-related nuclear cataracts in monozygotic and dizygotic twins. N Engl J Med. 2000;342(24):1786-1790.

7. Leske MC, Sperduto RD. The epidemiology of senile cataracts: a review. Am J Epidemiol. 1983;118(2):152-165.

8. Cumming RG, Mitchell P. Alcohol, smoking, and cataracts: the Blue Mountains Eye Study. Arch Ophthalmol. 1997;115(10):1296-1303.

9. Robman L, Taylor H. External factors in the development of cataract. Eye (Lond). 2005;19(10):1074-1082.

10. West SK, Duncan DD, Munoz B, et al. Sunlight exposure and risk of lens opacities in a population-based study: the Salisbury Eye Evaluation project. JAMA. 1998;280(8):714-718.

11. Munoz B, Tajchman U, Bochow T, West S. Alcohol use and risk of posterior subcapsular opacities. Arch Ophthalmol. 1993;111(1):110-112.

12. Nirmalan PK, Robin AL, Katz J, et al. Risk factors for age related cataract in a rural population of southern India: the Aravind Comprehensive Eye Study. Br J Ophthalmol. 2004;88(8):989-994.

13. Cumming RG, Mitchell P, Leeder SR. Use of inhaled corticosteroids and the risk of cataracts. N Engl J Med. 1997;337(1):8-14.

14. Klein BE, Klein R, Lee KE. Diabetes, cardiovascular disease, selected cardiovascular disease risk factors, and the 5-year incidence of agerelated cataract and progression of lens opacities: the Beaver Dam Eye Study. Am J Ophthalmol. 1998;126(6):782-790.

15. Tranquart F, Berges $\mathrm{O}$, Koskas $\mathrm{P}$, et al. Color Doppler imaging of orbital vessels: personal experience and literature review. J Clin Ultrasound. 2003;31(5):258-273.

16. Steigerwalt RD Jr, Laurora G, Incandela L, Cesarone MR, Belcaro GV, De Sanctis MT. Ocular and orbital blood flow in cigarette smokers. Retina. 2000;20(4):394-397.

17. Grieshaber MC, Kocak I, Dubler B, Flammer J, Orgul S. Retrobulbar blood flow in patients with cataract. Br J Ophthalmol. 2006;90(12): $1512-1515$.

18. Chang BY, Hee WC, Ling R, Broadway DC, Beigi B. Local anaesthetic techniques and pulsatile ocular blood flow. Br J Ophthalmol. 2000;84(11):1260-1263.

19. Huber KK, Remky A. Effect of retrobulbar versus subconjunctival anaesthesia on retrobulbar haemodynamics. Br J Ophthalmol. 2005;89(6):719-723.

20. Watkins R, Beigi B, Yates M, Chang B, Linardos E. Intraocular pressure and pulsatile ocular blood flow after retrobulbar and peribulbar anaesthesia. Br J Ophthalmol. 2001;85(7):796-798.

21. Glynn RJ, Rosner B, Christen WG. Evaluation of risk factors for cataract types in a competing risks framework. Ophthalmic Epidemiol. 2009; 16(2):98-106.

22. Hennis A, Wu SY, Nemesure B, Leske MC. Risk factors for incident cortical and posterior subcapsular lens opacities in the Barbados Eye Studies. Arch Ophthalmol. 2004;122(4):525-530.

23. Flammer J, Orgul S, Costa VP, et al. The impact of ocular blood flow in glaucoma. Prog Retin Eye Res. 2002;21(4):359-393.

\section{Dovepress}

PubMed Central and CAS, and is the official journal of The Society of Clinical Ophthalmology (SCO). The manuscript management system is completely online and includes a very quick and fair peer-review system, which is all easy to use. Visit http://www.dovepress.com/ testimonials.php to read real quotes from published authors. 